\title{
Decolorization of a recalcitrant organic compound (Melanoidin) by a novel thermotolerant yeast, Candida tropicalis RG-9
}

\author{
Soni Tiwari ${ }^{1}$, Rajeeva Gaur ${ }^{1 *}$ and Ranjan Singh ${ }^{2}$
}

\begin{abstract}
Background: Sugarcane distilleries use molasses for ethanol production and generate large volume of effluent containing high biological oxygen demand (BOD) and chemical oxygen demand (COD) along with melanoidin pigment. Melanoidin is a recalcitrant compound that causes several toxic effects on living system, therefore, may be treated before disposal. The aim of this study was to isolate a potential thermotolerant melanoidin decolorizing yeast from natural resources, and optimized different physico-chemical and nutritional parameters.

Results: Total 24 yeasts were isolated from the soil samples of near by distillery site, in which isolate Y-9 showed maximum decolorization and identified as Candida tropicalis by Microbial Type Culture Collection (MTCC) Chandigarh, India. The decolorization yield was expressed as the decrease in the absorbance at $475 \mathrm{~nm}$ against initial absorbance at the same wavelength. Uninoculated medium served as control. Yeast showed maximum decolorization (75\%) at $45^{\circ} \mathrm{C}$ using $0.2 \%$, glucose; $0.2 \%$, peptone; $0.05 \%$, MgSO4; $0.01 \%, \mathrm{KH}_{2} \mathrm{PO}_{4} ; \mathrm{pH}-5.5$ within $24 \mathrm{~h}$ of incubation under static condition. Decolorizing ability of yeast was also confirmed by high performance liquid chromatography (HPLC) analysis.

Conclusion: The yeast strain efficiently decolorized melanoidin pigment of distillery effluent at higher temperature than the other earlier reported strains of yeast, therefore, this strain could also be used at industrial level for melanoidin decolorization as it tolerated a wide range of temperature and $\mathrm{pH}$ with very small amount of carbon and nitrogen sources.
\end{abstract}

Keywords: Melanoidin, Decolorization, Thermotolerant, Candida tropicalis, Static condition

\section{Background}

Existing population bang globally urges rise of industrial sectors resulting in pollution of water, air and soil. The release of pollutants into the environment from various industries causes hazard to living organisms resulting in a greater environmental stress. One such industry of fast development is the distillery industry. There are more than 295 distilleries in India, producing approximately 2.7 billion liters of alcohol and releasing 40 billion liters of spentwash (distillery effluent) annually [1].

Dark brown color of distillery spentwash is mainly due to the presence of organic compound known as melanoidin [2]. Melanoidin is main content of spentwash and

\footnotetext{
* Correspondence: rajeevagaur@gmail.com

'Department of Microbiology (Centre of Excellence), Dr. Ram Manohar Lohia Avadh University, Faizabad 224001Uttar Pradesh, India

Full list of author information is available at the end of the article
}

is formed by the reaction between amino acid and carbohydrate called "Maillard reaction" [1,3]. These highly colored components hinder sunlight penetration in rivers, lakes or lagoons which inturn decrease both photosynthetic activity and dissolved oxygen concentration causing harm to aquatic life. Disposal of spentwash on land is equally hazardous causing a reduction in soil $\mathrm{pH}$, inhibition of seed germination and potable water [4].

The colored compound in spentwash has antioxidant properties and become toxic to all living system including microorganisms, therefore, must be treated before disposal into environment [5,6]; melanoidin can be removed by several common physico-chemical methods. Still, these methods require high reagent dosages and generate large amount of sludge $[7,8]$. Biological methods present an incredible alternate for decolorization/

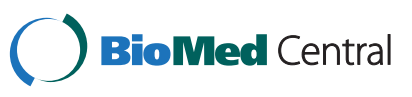


degradation of spentwash due to their low cost, environmental friendly and publicly acceptable treatment and cost-competitive alternative to chemical decomposition processes $[8,9]$.

A number of biological processes such as bioadsorption and biodegradation have been reported having prospective application in color removal from spentwash [10-16]. A wide variety of aerobic microorganisms capable of decolorizing spentwash include bacteria, fungi, cyanobacteria and yeasts. Some bacterial strains isolated from sewage and acclimatized on increasing concentrations of distillery waste, which were able to reduce chemical oxygen demand (COD) by $80 \%$ in $4-5$ days without any aeration and the major products left after the degradation process were biomass, carbon dioxide and volatile acids [17]. Raghukumar and Rivonkar [18] isolated a marine fungus, Flavodon flavus, which was more effective in decolorizing raw molasses spentwash than was the molasses wastewater collected either after anaerobic treatment or after aerobic treatment. Tondee and Sirianutapiboon [19] isolated Issatchenkia orientalis yeast from fruit sample which showed $60 \%$ melanoidin decolorization at $30{ }^{\circ} \mathrm{C}$ in 7 days under aerobic condition.

In the present investigation, an attempt was made to isolate such strain from natural ecosystem which has ability to grow at higher temperature with minimum expense of simple sugar and higher percentage of melanoidin decolorization ability.

\section{Results and discussion}

\section{Isolation, screening and identification of the isolates}

A total of 24 yeast isolates capable of dye decolorization were isolated on the GPYE agar medium from the soil of distillery near by the Masudha distillery Faizabad, India. The isolates showing higher clear zone around the colony on GPYE agar were selected for further study $(\mathrm{pH}$ $5.5,24-48 \mathrm{~h}$ and $45{ }^{\circ} \mathrm{C}$ ). The clear zone diameter of more than $1 \mathrm{~cm}$ around the colony was considered as effective isolates for decolorization (data not shown).

For further study, isolates were inoculated in $50 \mathrm{ml}$ of medium and incubated at $35^{\circ} \mathrm{C}$ and $45^{\circ} \mathrm{C}$ for $24-48 \mathrm{~h}$ for selection of thermotolerant melanoidin decolorizing yeast individually. Among yeast isolates, higher decolorization (67\%) was shown by yeast isolate Y-9 identified by MTCC Chandigarh as Candida tropicalis RG-9. However, this isolate of yeast was separately optimized for higher decolorization at different medium with varying contents of carbon, nitrogen sources and their different concentrations.

The effect of medium composition on decolorization by yeast is clear as mentioned in Figure 1. Yeast strain showed higher melanoidin decolorization (67\%) in medium B $(0.5 \%$, glucose; $0.2 \%$, yeast extract; $0.3 \%$,

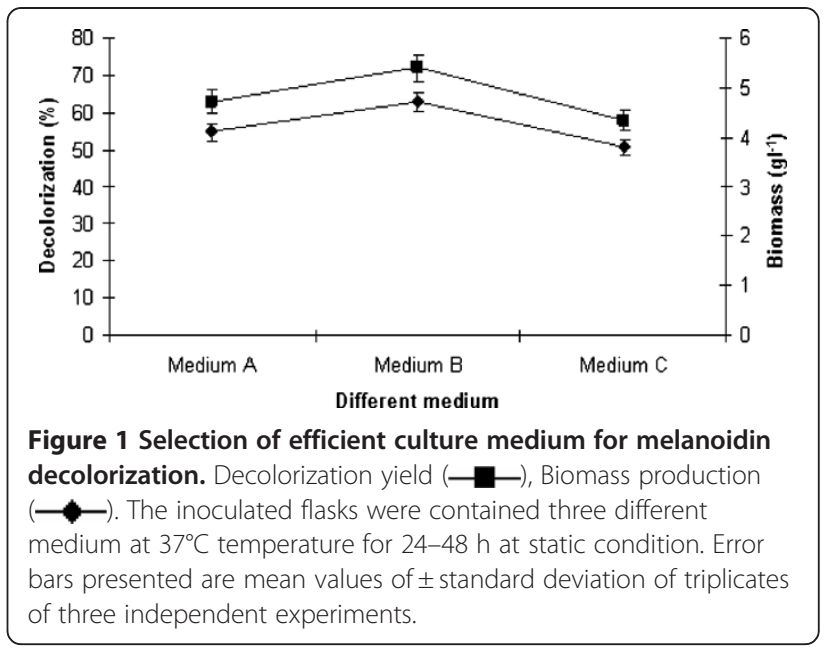

peptone; $0.05 \%, \mathrm{MgSO}_{4} ; 0.05 \%, \mathrm{~K}_{2} \mathrm{HPO}_{4}$ with $3.5 \mathrm{OD}$ effluent) when compared to medium A and C. Medium B was found most suitable because this medium could provide more organic form of nitrogen source than others. Therefore, nitrogen requirement by the isolate was higher for better decolorization, this could probably by improving metabolic activities for enzyme secretion or the biomass could be promoted. However, medium B was selected for optimization of physico-chemical and nutritional parameters for melanoidin decolorization by yeast strain Y-9 (Figure 1).

\section{Effect of different temperature on melanoidin decolorization}

The influence of temperature regime on melanoidin decolorization and biomass production was studied by varying the temperature from $25^{\circ} \mathrm{C}$ to $50^{\circ} \mathrm{C}$ while other

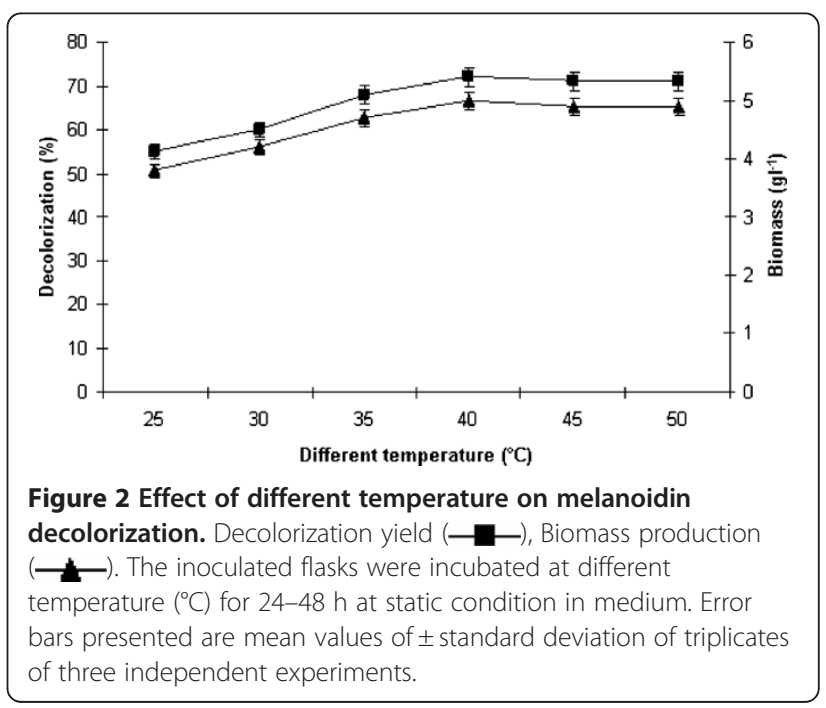


parameters were maintained constant. From Figure 2 it was observed that melanoidin decolorization by yeast strain Y-9 was active at all temperatures employed with maximum decolorization at $40^{\circ} \mathrm{C}$ to $50^{\circ} \mathrm{C}$. It exhibited $72 \%$ decolorization with $5.0 \mathrm{gl}^{-1}$ biomass production. The remarkable decolorization $(72 \%)$ in the temperature range of $40-50^{\circ} \mathrm{C}$ reveals thermotolerant as well as mesophilic nature of the yeast strain. Our strain showed better decolorization potential at higher temperature than Sirianuntapiboon et al. [20] who reported a maximum of $68 \%$ spentwash decolorization at $30^{\circ} \mathrm{C}$ by Citeromyces sp. WR-43-6. Similarly, Tondee and Sirianutapiboon. [19] reported that Issatchenkia orientalis showing maximum $60 \%$ spentwash decolorization at $30^{\circ} \mathrm{C}$. Further, increase in temperature could not affect the biomass production as well as decolorization efficiency by yeast strain Y-9. According to Cetin and Donmez [21], high temperature may cause loss in cell viability or deactivation of the enzymes responsible for decolorization resulted into suppressed decolorizing activity. Therefore, the melanoidin decolorization and biomass production efficiency of our strain Y-9 was certainly better than reported by other researchers. Thus, it may be suggested that the optimal temperature for melanoidin decolorization depends on the variation of microbial strains and their genetic diversity as they have been isolated from a very wide range of climatic conditions.

\section{Effect of different time course on melanoidin decolorization}

Time course of melanoidin decolorization was studied alongwith biomass production of yeast strain Y-9. Maximum decolorization (72\%) was achieved in $24 \mathrm{~h}$ of incubation with $4.95 \mathrm{gl}^{-1}$ biomass production (Figure 3). Further increase in the incubation period did not increase the decolorization. On contrary Tondee and Sirianutapiboon. [19] reported 60\% decolorization by Issatchenkia orientalis, but after 7 days of incubation. In another study Sirianuntapiboon et al. [20] had been reported a maximum 68\% decolorization using Citeromyces sp. WR43-6 after 7 days of incubation. Therefore, decolorization and growth efficiency of our strain Y-9 is certainly better than that reported by other researchers.

\section{Effect of different $\mathrm{pH}$ on melanoidin decolorization}

The influence of $\mathrm{pH}$ on melanoidin decolorization and biomass production was studied at varying $\mathrm{pH}$ from 4.0 to 7.0 at their optimal temperature and incubation period. Maximum $72 \%$ decolorization was achieved at pH 5.5 with $4.95 \mathrm{gl}^{-1}$ biomass production (Figure 4). Strain Y-9 exhibited its optimal decolorization at $\mathrm{pH} 5.5$ and any deviation from optimum level of $\mathrm{pH}$ reduced the melanoidin decolorization activity. The decrease in decolorization activity was drastic towards more acidic $\mathrm{pH}$ leading to no activity at $\mathrm{pH}$ 3.0-4.0. Melanoidin decolorization from other yeast strain was also reported by several researchers having maximum decolorization activity in 5.0-6.0 optimum pH range [19,20]. Several workers have studied that enzymes produced by microorganism during the decolorization were effective only in acidic conditions [22]. An increase in color at higher $\mathrm{pH}$ was due to the polymerization of melanoidin and higher rate nutrient utilization [23,24]. Similar results have been reported when soil samples were used as inoculum instead of isolated organisms $[23,25,26]$. Melanoidin decolorization got reduced at above and below of this $\mathrm{pH}$ due to inhibition of enzyme production as well as activity. All enzymes are protein in nature, therefore, some proteins denatured at higher or lower $\mathrm{pH}$ value. Each microorganism has a specific $\mathrm{pH}$ for their

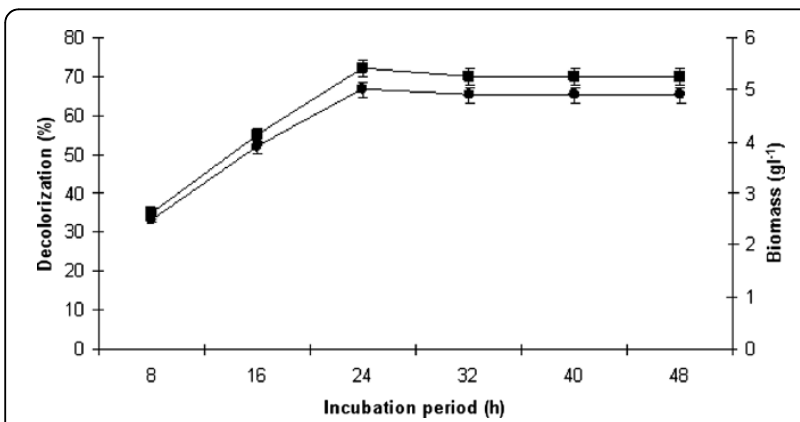

Figure 3 Effect of different incubation periods on melanoidin decolorization. Decolorization yield (- - ), Biomass production (-). The inoculated flasks were incubated at different incubation period at $45^{\circ} \mathrm{C}$ under static condition in medium. Error bars presented are mean values of \pm standard deviation of triplicates of three independent experiments.

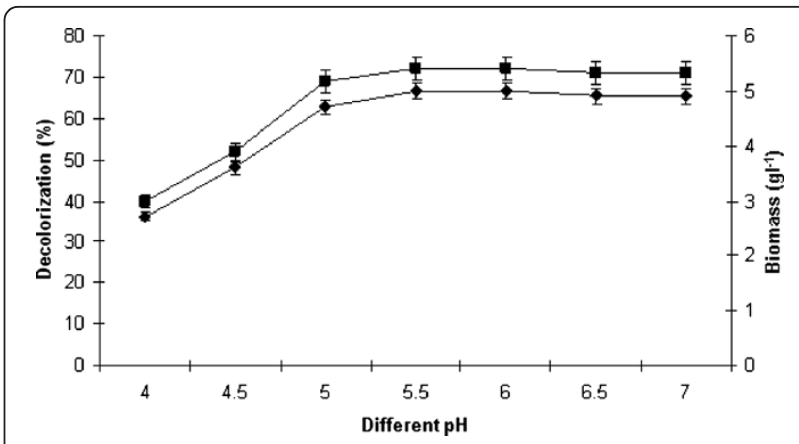

Figure 4 Effect of different $\mathrm{pH}$ on melanoidin decolorization. Decolorization yield ( $\longrightarrow$ ), Biomass production $(-\bullet)$. The inoculated flasks were incubated at different $\mathrm{pH}$ at $45^{\circ} \mathrm{C}$ for $24 \mathrm{~h}$ under static condition in medium. Error bars presented are mean values of \pm standard deviation of triplicates of three independent experiments. 
growth and enzyme activity in the surrounding environment. Therefore, the physiological function of yeast varies from strain to strain.

\section{Effect of different carbon sources on melanoidin decolorization}

In another approach, the effect of various carbon sources $(0.5 \%, \mathrm{w} / \mathrm{v})$ on melanoidin decolorization and biomass production was also investigated for $24 \mathrm{~h}$ of incubation, and the results are depicted in Figure 5. Melanoidin decolorization by yeast strain Y-9 is extraordinarily stable in the presence of all carbon sources under study. It was observed that except lactose, presence of other carbon sources enhanced the melanoidin decolorization when compared to control (without carbon source). With control (without carbon source), sucrose, glucose, fructose and starch, yeast strain Y-9 showed $70,72,74,73$, and $72 \%$ decolorization, respectively. The presence of lactose marginally reduced decolorization. From Figure 5 it was observed that higher decolorization (74\%) and biomass $\left(5.0 \mathrm{gl}^{-1}\right)$ was reported by glucose when compared to control (without sugar), while fructose favored the decolorization. Melanoidin decolorization from other yeast are maximum in the presence of glucose have reported by others researchers also [19,20]. Watanabe et al. [27] have reported the enzymatic degradation of melanoidin by Coriolus sp. No. 20 having an intracellular enzyme, which required active oxygen molecules and sugars (sorbose as well as glucose) in reaction mixture, was later identified as sorbose oxidase which oxidize glucose into gluconic acid. It is, therefore, evident from our study that melanoidin decolorization by yeast strain Y-9 is remarkably stable in the presence of broad range of carbon sources employed in this study.

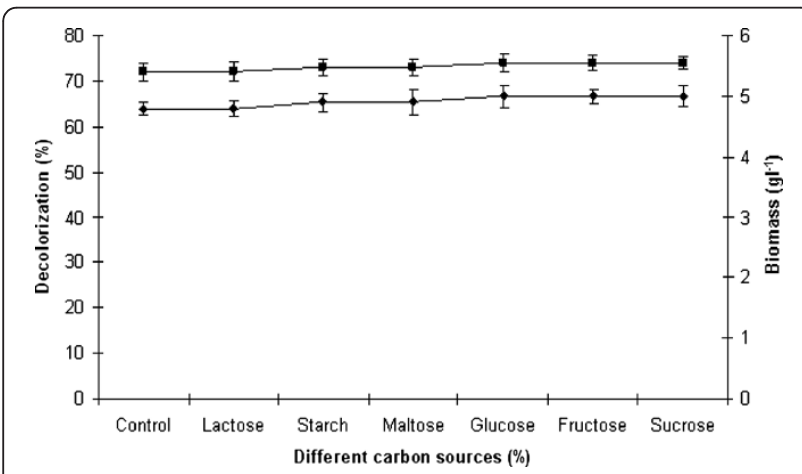

Figure 5 Effect of different carbon sources on melanoidin decolorization. Decolorization yield ( - -), Biomass production $(-)$. The control flask does not contain any carbon sources. Test flasks contained different carbon sources in the medium at a level of $0.5 \%(\mathrm{w} / \mathrm{v})$. Inoculated flasks were incubated at $45^{\circ} \mathrm{C}$ for $24 \mathrm{~h}$. Error bars presented are mean values of \pm standard deviation of triplicates of three independent experiments.
Effect of different concentration of glucose on melanoidin decolorization

In another set of the experiment, the effect of various concentration of glucose $(0.1,0.2,0.3,0.4,0.5$ and $0.6 \%$, $\mathrm{w} / \mathrm{v})$ on melanoidin decolorization and biomass production was also investigated and the results are depicted in Figure 6. Melanoidin decolorization by yeast strain Y-9 is extraordinarily stable in the presence of all glucose concentrations under study. It was observed that glucose concentration above $0.3 \%(\mathrm{w} / \mathrm{v})$, decreased the melanoidin decolorization. From Figure 6 it was observed that maximum $75 \%$ decolorization with $5.0 \mathrm{~g} \mathrm{l}^{-1}$ biomass production was achieved at $0.2 \%(\mathrm{w} / \mathrm{v})$ glucose concentration, above this concentration decolorization reduced and biomass was slightly increased. This effect can be explained as during initial phase of growth organism utilizes easily available carbon sources added to the medium and then starts to degrade spentwash components for carbon source [11]. Tondee and Sirianutapiboon. [19] have also reported that Issatchenkia orientalis utilized 2.5\% glucose for maximum decolorization (60\%) and above this concentration of glucose there was decrease in the decolorization. Similarlly, Sirianuntapiboon et al. [20] have reported that Citeromyces sp. WR-43-6 showed 68\% decolorization in the presence of $2.0 \%$ glucose concentration. Ohmomo et al. [10] have reported that glucose was the best carbon source, which utilized by Aspergillus fumigatus G-2-6 for maximum degradation of melanoidin and further increase in glucose concentration resulted in an increase in mycelial biomass but no further increase in decolorization yield. It is, therefore, evident from our study that melanoidin decolorization by yeast strain Y-9 is remarkably higher in the presence of $0.2 \%(\mathrm{w} / \mathrm{v})$ glucose within $24 \mathrm{~h}$ of incubation when compared to other researchers.

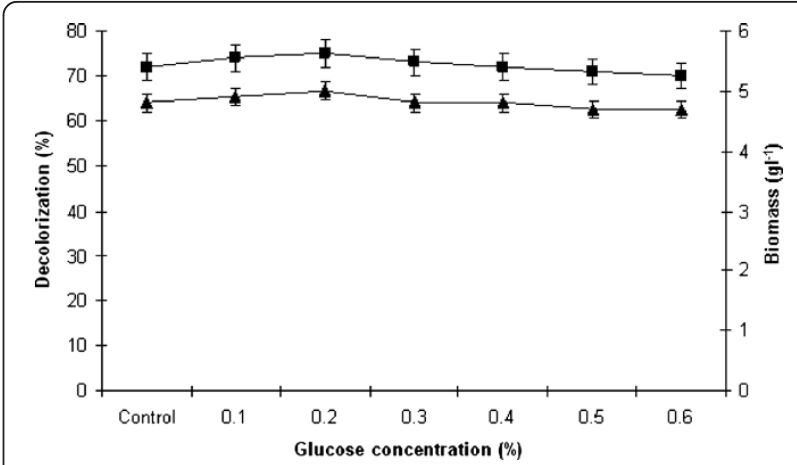

Figure 6 Effect of different glucose concentration on melanoidin decolorization. Decolorization yield ( $\longrightarrow$-), Biomass production (- $(-)$. The control flask does not contain glucose. Test flasks contained different concentration of glucose in the medium at a level of $0.6 \%(\mathrm{w} / \mathrm{v})$. Inoculated flasks were incubated at $45^{\circ} \mathrm{C}$ for $24 \mathrm{~h}$. Error bars presented are mean values of \pm standard deviation of triplicates of three independent experiments. 


\section{Effect of different nitrogen sources on melanoidin decolorization}

The influence of various organic and inorganic nitrogen sources $(0.5 \%, \mathrm{w} / \mathrm{v})$ on melanoidin decolorizatin and biomass production was also investigated for $24 \mathrm{~h}$ of incubation, and the results are depicted in Figure 7 . Melanoidin decolorization by yeast strain Y-9 is extraordinarily stable in the presence of all nitrogen sources under study. It was observed that except sodium nitrate and beef extract, presence of other nitrogen sources enhanced the melanoidin decolorization when compared to control (without nitrogen source). From Figure 7 it observed that yeast strain showed higher 75\% decolorization with $4.95 \mathrm{gl}^{-1}$ biomass production in the presence of peptone, it was practically high compared to the extent of decolorization reported by other workers [8]. Sirianuntapiboon et al. [28] have reported that yeast extract and peptone inducing decolorizing activity in acetogenic bacterium strain No. BP103. But in case of Issatchenkia orientalis and Citeromyces sp. WR-43-6, maximum decolorization was reported in the presence of $0.1 \% \mathrm{NH}_{4} \mathrm{Cl}$ and $0.1 \%$ sodium nitrate $[19,20]$. Kirk et al. [29] have reported that enzymatic systems catalyze degradation of lignin and lignin-like materials during the secondary phase of the metabolic growth in the presence of peptone. Synthesis and secretion of lignin peroxidase or ligninase (LiP) and manganese-dependent peroxidase $(\mathrm{MnP})$ are triggered by nutrient limitations such as carbon and nitrogen sources.

\section{Effect of different concentration of peptone on melanoidin decolorization}

In another set of the experiment, the effect of various concentration of peptone $(0.1,0.2,0.3,0.4,0.5$ and $0.6 \%$,

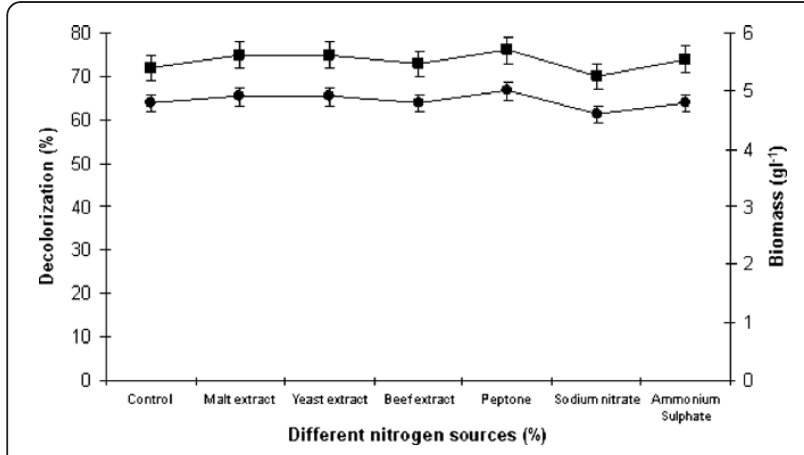

Figure 7 Effect of different nitrogen sources on melanoidin decolorization. Decolorization yield ( - -), Biomass production (-). The control flask does not contain any nitrogen sources. Test flasks contained different nitrogen sources in the medium at a level of $0.5 \%(\mathrm{w} / \mathrm{V})$. Inoculated flasks were incubated at $45^{\circ} \mathrm{C}$ for 24 h. Error bars presented are mean values of \pm standard deviation of triplicates of three independent experiments. w/v) on melanoidin decolorization and biomass production was also investigated and the results are depicted in Figure 8 . Melanoidin decolorization by yeast strain Y-9 is extremely stable in the presence of all peptone concentrations under study. It was observed that peptone concentration above $0.3 \%(\mathrm{w} / \mathrm{v})$, decreased the melanoidin decolorization. From Figure 8 it was observed that maximum $75 \%$ decolorization with $5.0 \mathrm{gl}^{-1}$ biomass production was achieved at $0.2 \% \quad(\mathrm{w} / \mathrm{v})$ peptone concentration, above this concentration reduced decolorization. Similarly Ravikumar et al. [26] have also reported that cladosporium cladosporioides showed maximum decolorization at low concentration of peptone $\left(1.0 \mathrm{gl}^{-1}\right)$ because at high concentration there was no significance in decolorization due to surplus supplementation of nitrogen which inhibition the growth. Similar effect was observed when low concentration of peptone was used as nitrogen source by Phanerochaete Chrysosporium for decolorization of melanoidin pigment present in spentwash [5]. It is, therefore, evident from our study that melanoidin decolorization by yeast strain Y-9 is remarkably higher in the presence of $0.2 \%$ (w/v) peptone within $24 \mathrm{~h}$ of incubation. This culture utilized little amount of peptone for higher melanoidin decolorization compared to other researchers ever reported.

\section{HPLC analysis}

The HPLC analysis report representing the area, height, retention time, before and after the treatment of spentwash (Figure 9a and b) which confirms the biodegradation of melanoidin, main compound/pigment responsible for dark brown color of distillery effluent. A major peak appeared at a retention time of $2.60 \mathrm{~min}$ in treated sample which was less compared to untreated and clearly indicates the ability of the yeast to decolorize/degrade the spentwash. The reduction in physico-chemical characteristics

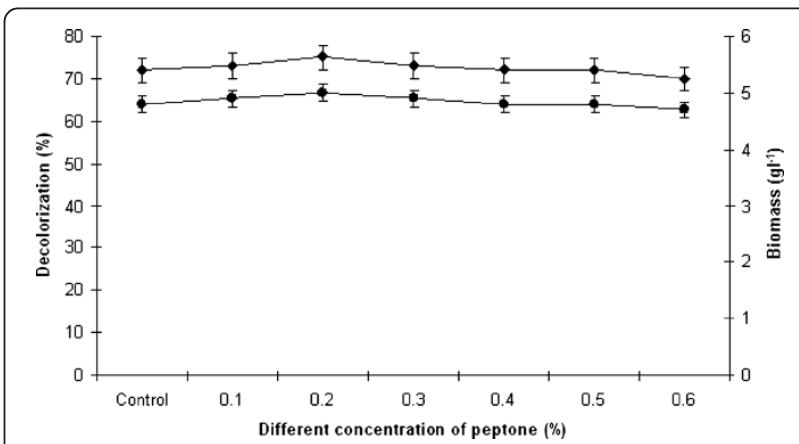

Figure 8 Effect of different peptone concentration on melanoidin decolorization. Decolorization yield (—-), Biomass production (-). The control flask does not contain peptone. Test flasks contained different concentration of peptone in the medium at a level of $0.6 \%(\mathrm{w} / \mathrm{v})$. Inoculated flasks were incubated at $45^{\circ} \mathrm{C}$ for $24 \mathrm{~h}$. Error bars presented are mean values of \pm standard deviation of triplicates of three independent experiments. 

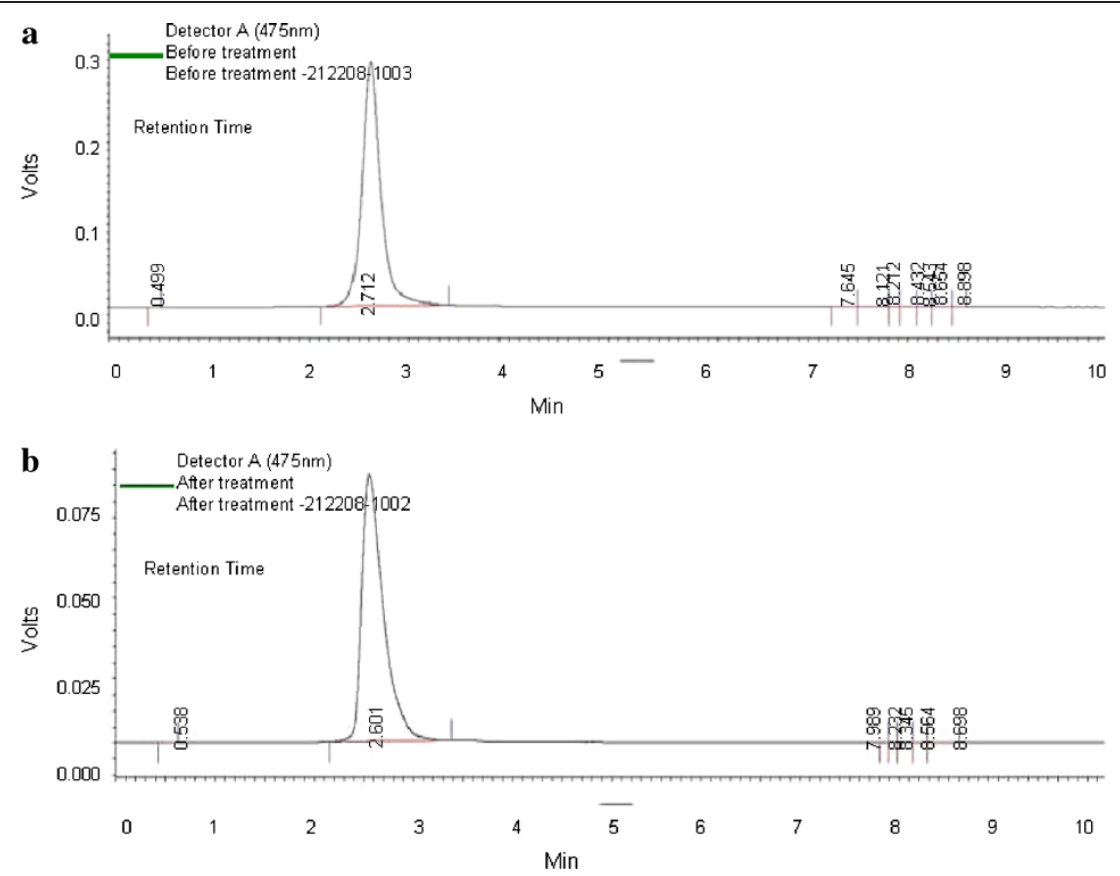

Figure 9 HPLC analysis for monitoring the spentwash decolorization. 9(A) HPLC analysis for distillery spentwash before treatment showing a maximum peak with 2.712 retention time, 3916140 area and 276697 height. 9(B) HPLC analysis for distillery spentwash after treatment showing a maximum peak with 2.601 retention time, 1253879 area and 84452 height.

may be due to degradation of melanoidin in the presence of carbon and nitrogen sources through metabolism.

\section{Conclusion}

The thermotolerant Candida tropicalis has ability to decolorized complex melanoidin compound at wide range of temperature and $\mathrm{pH}$ in presence of little amount of carbon and nitrogen sources within a short incubation period of $24 \mathrm{~h}$. This strain has ability to reduce environment pollution by decolorizing melanoidin pigment with cost effective and eco-friendly nature.

\section{Materials and methods \\ Distillery spent wash (DSW)}

The molasses spent wash was collected aseptically from Masuadha sugarcane distillery, faizabad U.P., India. The spentwash was centrifuged at $10,000 \mathrm{rpm}$ for $15 \mathrm{~min}$ before use to remove the suspended solids and stored at $4^{\circ} \mathrm{C}$. The stored distillery spentwash was filtered through (Whatman No: 1) filter paper and was diluted with distilled water [25]. The analysis of different physico-chemical parameters like color, odor, $\mathrm{pH}$, biological oxygen demand (BOD), chemical oxygen demand (COD), total sugars, total dissolved solids (TDS), sulphates, phosphorous and calcium were analyzed for employing standard methods for examination of water and wastewater [30] and is shown in Table 1.
Isolation, screening and identification of melanoidindecolorizing yeast

Melanoidin decolorizing yeast isolated from soil sample collected from distillery was grown on GPYE agar medium for 24 to $48 \mathrm{~h}$ incubation. Culture medium consisted of $0.2 \%, \mathrm{~K}_{2} \mathrm{HPO}_{4} ; 0.1 \%, \mathrm{KH}_{2} \mathrm{PO}_{4} ; 0.01 \%$, $\mathrm{MgSO}_{4} .12 \mathrm{H}_{2} \mathrm{O} ; 0.5 \%$, glucose and $0.1 \%$, yeast extract

Table 1 Physico-chemical properties of distillery effluent (spentwash)

\begin{tabular}{|c|c|}
\hline Parameters & Value of distillery effluent \\
\hline Color & Dark brown \\
\hline Odour & Like molasses \\
\hline Temperature ${ }^{\circ} \mathrm{C}$ & 82 \\
\hline $\mathrm{pH}$ & 4.2 \\
\hline Total dissolved solid ( $\mathrm{mg} \mathrm{l}^{-1}$ ) & 81733 \\
\hline Total suspended solid $\left(\mathrm{mg} \mathrm{I}^{-1}\right)$ & 5933 \\
\hline Dissolved oxygen $\left(\mathrm{mg} \mathrm{l}^{-1}\right)$ & 0 \\
\hline Biological oxygen demand $\left(m g \mathrm{I}^{-1}\right)$ & 46666 \\
\hline Chemical oxygen demand $\left(\mathrm{mg} \mathrm{I}^{-1}\right)$ & 104130 \\
\hline Total nitrogen $\left(\mathrm{mg} \mathrm{l}^{-1}\right)$ & 1635 \\
\hline Phosphorus (mg $\mathrm{I}^{-1}$ ) & 163 \\
\hline Potassium (mg |-1) & 8766 \\
\hline Sodium $\left(\mathrm{mg} \mathrm{I}^{-1}\right)$ & 211 \\
\hline Calcium (mg ${ }^{-1}$ ) & 1816 \\
\hline Sulphate $\left(\left.m g\right|^{-1}\right)$ & 1738 \\
\hline
\end{tabular}


with 3.5 OD effluent and the initial $\mathrm{pH}$ was adjusted to 5.5. In order to isolate molasses decolorizing yeast, $1.0 \mathrm{~g}$ of soil was serially dilution upto $10^{-5}$ to $10^{-6}$ and placed in Petri plates along with the GPYE agar medium. The plates were subsequently incubated for $24-48 \mathrm{~h}$ at $35 \pm 2^{\circ} \mathrm{C}$ and $45 \pm 2^{\circ} \mathrm{C}$ for thermotolerant yeast. After 24-48 h of incubation, decolorization efficiency was recorded visually. The isolates showing more decolorization of the melanoidin were selected for further studies, maintained on the same medium at $4^{\circ} \mathrm{C}$ in slants, and subcultured after two weeks. These cultures were identified at genus and species level by Institute of Microbial Technology (IMTECH) MTCC Chandigarh, India.

\section{Inoculum preparation}

Mother culture was prepared by inoculating one full loop of $24 \mathrm{~h}$ grown culture on basal agar plate in $50 \mathrm{ml}$ basal broth, and incubated at $37^{\circ} \mathrm{C}$ for $24 \mathrm{~h}$ to achieve active exponential phase consisting of $50 \times 10^{6} \mathrm{cfu} \mathrm{m}^{-1}$ population. Appropriate volume $(0.5 \%, \mathrm{v} / \mathrm{v})$ of this cell suspension was used to inoculate the test flasks.

\section{Decolorization assay}

The melanoidin decolorizing yeast was inoculated in the GPYE broth medium and after incubation; broth was centrifuged at 10,000 rpm for $10 \mathrm{~min}$. The supernatant of the centrifuged sample was read at absorbance maximum $\left(\mathrm{A}_{\max }\right)$ of the melanoidin i.e. $475 \mathrm{~nm}$ using spectrophotometer [31]. The decolorization yield was expressed as the decrease in the absorbance at $475 \mathrm{~nm}$ against initial absorbance at the same wavelength. Uninoculated medium served as control. The entire assays were performed in triplicate and compared with control. The decolorization efficiency of the isolate was expressed as per following equation:

$$
\text { Decolorization }(\%)=\mathrm{I}-\mathrm{F} / \mathrm{I}
$$

Where, I = Initial absorbance (Control) and $\mathrm{F}=\mathrm{Ab}$ sorbance of decolorized medium broth.

\section{Biomass determination}

Yeast cells in broth were collected by centrifugation $\left(10,000 \mathrm{rpm}\right.$ for $10 \mathrm{~min}$ at $\left.4^{\circ} \mathrm{C}\right)$, washed with distilled water, and dried in an oven at $80^{\circ} \mathrm{C}$ until getting a constant dried weight reported in the form of dry cell mass $\left(\mathrm{g} \mathrm{l}^{-1}\right)$.

\section{Selection of efficient medium for melanoidin decolorization}

An experiment was conducted to select a suitable medium for efficient decolorization by the yeast strain. The medium having various combinations of glucose, peptone and effluent was used to evaluate decolorization potential of the isolate. Three types of media with different composition were used to evaluate.

Medium A: - Distillery effluent without carbon and nitrogen supplemented medium with 3.5 OD.

Medium B:- $0.5 \%$, glucose; $0.2 \%$, yeast extract; $0.3 \%$, peptone; $0.05 \%, \mathrm{MgSO}_{4} ; 0.05 \%, \mathrm{~K}_{2} \mathrm{HPO}_{4}$ with $3.5 \mathrm{OD}$ effluent.

Medium C: - $0.6 \%$, glucose; $0.5 \%$, peptone; $0.05 \%$, $\mathrm{MnSO}_{4} ; 0.05 \%, \mathrm{~K}_{2} \mathrm{HPO}_{4}$ with $3.5 \mathrm{OD}$ effluent respectively.

\section{Selection of Physico-chemical and nutritional parameters for melanoidin decolorization Optimization of experimental conditions}

The various process parameters influencing melanoidin decolorization and biomass production by fermentation were optimized individually and independently of the others, therefore, the optimized conditions were subsequently used in all the experiments in sequential order. For optimization, the basal medium contained glucose $0.5 \%$; peptone $0.2 \%$; yeast extract $0.3 \%$; $\mathrm{K}_{2} \mathrm{HPO}_{4} 0.05 \%$ and $\mathrm{MgSO} 40.05 \%$ with $3.5 \mathrm{OD}$ spentwash at $\mathrm{pH}-5.5$ was used for inoculation with $0.5 \%(\mathrm{v} / \mathrm{v})$ of yeast culture having $50 \times 10^{6} \mathrm{cfu}$ ml-1 and then incubated for different periods viz. $8,16,24,32,40$ and $48 \mathrm{~h}$ at different temperature viz. $25,30,35,40,45$ and $50^{\circ} \mathrm{C}$. For melanoidin decolorization all the experiments were carried out under static. Initial $\mathrm{pH}$ also plays an important role in melanoidin decolorization and biomass production, so $\mathrm{pH}$ of medium was adjusted to 4.0, 4.5, 5.0, 5.5, 6.0, 6.5 and 7.0 using either $1 \mathrm{~N} \mathrm{HCl}$ or $1 \mathrm{~N} \mathrm{NaOH}$. For the optimal melanoidin decolorization and biomass production, the strains may require additional carbon and nitrogen sources with varying concentrations in its growth media. Therefore, the growth medium was supplemented with the carbon sources viz. glucose, fructose, sucrose, maltose, lactose and starch (at the level of $0.5 \%$, $\mathrm{w} / \mathrm{v}$ ) and nitrogen sources viz. ammonium sulphate, yeast extract, peptone, beef extract, malt extract, sodium nitrate, and sodium nitrite (at the level of $0.5 \%, \mathrm{w} / \mathrm{v}$ ). Thereafter, optimized carbon and nitrogen sources were further optimized at different concentration $(0.1$ to $0.6 \%$, $\mathrm{w} / \mathrm{v})$. The fermentation medium was sterilized at $121^{\circ} \mathrm{C}$ for $15 \mathrm{~min}$ and incubation was done at $45^{\circ} \mathrm{C}$ with all the other conditions at the optimal levels determined previously.

\section{HPLC analysis of spentwash}

Decolorization of melanoidin (spentwash) was monitored by HPLC (Shimadzu). $10 \mathrm{ml}$ of samples were taken, and centrifuged, filtered through $0.45 \mu \mathrm{m}$ membrane filter (Millipore). Filtered sample was analyzed using mobile phase consisting acetonitryl and methanol (45:55) (HPLC grade) with $1 \mathrm{ml}$ glacial acid and $0.5 \mathrm{ml}$ 
sodium acetate $[26,32]$. The sample was eluted using C18; reverse phase column of $5 \mu \mathrm{m}$ SGE, $250 \times 4.6 \mathrm{~mm}$ SS. Resultant peak was analyzed with UV-detector $475 \mathrm{~nm}$. The flow rate of the mobile phase was

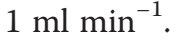

\section{Statistical analysis}

All experiments were carried out in triplicates and the results are presented as the mean of three independent observations. Standard deviation for each experimental result was calculated using Microsoft Excel.

\section{Competing interests}

The author(s) declare that they have no competing interests.

\section{Authors' contributions}

ST carried out the research work and drafted the manuscript. RS was involved in revising the manuscript critically for important intellectual content. RG has designed the experiment, contributed substantially to analysis and interpretation of data and have given final approval of the version to be published. All authors read and approved the final manuscript.

\section{Acknowledgement}

Financial assistance to the author (Soni Tiwari, Rajeeva Gaur and Ranjan Singh) by Council of Science and Technology, U.P., in the form of Major Research Project is thankfully acknowledged.

\section{Author details}

${ }^{1}$ Department of Microbiology (Centre of Excellence), Dr. Ram Manohar Lohia Avadh University, Faizabad 224001Uttar Pradesh, India. ${ }^{2}$ Amity Institute of Microbial Biotechnology, Amity University, NoidaG. B. NagarUttar Pradesh, India.

Received: 6 March 2012 Accepted: 22 May 2012

Published: 18 June 2012

\section{References}

1. Naik N, Jagadeesh KS, Noolvi MN: Enhanced Degradation of Melanoidin and Caramel in Biomethanated Distillery Spentwash by Microorganisms Isolated from Mangroves. Iranica J Ener Environ 2010, 1:347-351.

2. Ohmomo S, Aoshima I, Tozawa Y, Sakurada N, Ueda K: Purification and some properties of melanoidin decolourizing enzymes, P-III and P-IV, from mycelia of Coriolus vericolour Ps4a. Agric Biol Chem 1985, 49:2047-2053.

3. Wedzicha BL, Kaputo MT: Melanoidins from glucose and glycine: Composition, characteristics and reactivity towards sulphite ion. Food Chem 1992, 43:359-367.

4. Agrawal CS, Pandey GS: Soil pollution by spentwash discharge: Depletion of manganese (II) and impairment of its oxidation. J Environ Biol 1994, 15:49-53.

5. Dahiya J, Singh D, Nigam P: Decolourisation of synthetic and spentwash melanoidins using the white-rot fungus Phanerochaete chrysosporium JAG-40. Biores Technol 2001, 78:95-98.

6. Chandra R, Bharagava RN, Rai V: Melanoidins as major colourant in sugarcane molasses based distillery effluent and its degradation. Biores Technol 2008, 99:4648-4660.

7. Pena M, Coca M, Gonzalez R, Rioja R, Garcia MT: Chemical oxidation of wastewater from molasses fermentation with ozone. Chemosphere 2003, 51:893-900.

8. Mohana S, Desai C, Datta M: Biodegradation and decolorization of anaerobically treated distillery spent wash by a novel bacterial consortium. Biores Technol 2007, 98:333-339.

9. Moosvi S, Keharia H, Madamwar D: Decolorization of textile dye reactive violet 5 by a newly isolated bacterial consortium RVM 11.1. World J Microbiol Biotechnol 2005, 21:667-672.

10. Ohmomo S, et al: Decolourization of molasses wastewater by a thermophilic strain Aspergillus fumigatus G-2-6. Agric Biol Chem 1987, 51:3339-3346.

11. Kumar $V$, et al: Bioremediation and decolorization of anaerobically digested distillery spentwash. Biotechnol 1997, 19:311-313.
12. Kumar $P, C$ Chandra R: Decolourization and detoxification of synthetic molasses melanoidins by individual and mixed cultures of Bacillus spp. Biores Technol 2006, 97:2096-2102.

13. Plavsic M, Cosovic B, Lee C: Copper complexing properties of melanoidins and marine humic material. Sci Total Environ 2006, 366:310-319.

14. Pant D, Adholeya A: Biological approaches for treatment of distillery wastewater: a review. Biores Technol 2007, 98:2321-2334.

15. Nwuche CO, Ugoji EO: Effects of heavy metal pollution on the soil microbial activity. Int J Environ Sci Tech 2008, 5:409-414.

16. Nwuche CO, Ugoji EO: Effect of co-existing plant specie on soil microbial activity under heavy metal stress. Int J Environ Sci Tech 2010, 7:697-704.

17. Kumar S, Viswanathan L: Production of biomass, carbon dioxide, volatile acids, and their interrelationship with decrease in chemical oxygen demand, during distillery waste treatment by bacterial strains. Enz Microb Technol 1991, 13:179-186.

18. Raghukumar C, Rivonkar G: Decolourization of molasses spent wash by the white-rot fungus Flavodon flavus, isolated from a marine habitat. Appl Microbiol Biotechnol 2001, 55:510-514.

19. Tondee T, Sirianutapiboon S: Screening of melanoidin decolorization activity in yeast strain. Int Conf Environ 2006, 99:5511-5519.

20. Sirianuntapiboon S, Zohsalam P, Ohmomo S: Decolorization of molasses wastewater by Citeromyces sp. WR-43-6. Process Biochem 2004, 39:917-924.

21. Cetin D, Donmez G: Decolorization of reactive dyes by mixed cultures isolated from textile effluent under anaerobic conditions. Enzym Microbial Technol 2006, 38:926-930.

22. Seyis I, Subasing T: Screeming of different fungi for decolorization of molasses. Brazilian J Microbiol 2009, 40:61-65.

23. Adikane HV, Dange MN, Selvakumari K: Optimization of anaerobically digested distillery molasses spent wash decolorization using soil as inoculum in the absence of additional carbon and nitrogen source. Biores Technol 2006, 97:2131-2135.

24. Jiranuntipon S, Chareonpornwattana S, Damronglerd S, Albasi C, Delia ML: Decolorization of synthetic Melanoidins-Containing Wastewater by a Bacterial Consortium. Ind Microbiol Biotechnol 2008, 35:1313-1321.

25. Pazouki M, Shayegan J, Afshari A: Screening of microorganisms for decolorization of treated distillery wastewater. Iran J Sci Technol 2008, 32:53-60.

26. Ravikumar R, Vasanthi NS, Saravanan K: Single factorial experimental design for decolorizing anaerobically treated distillery spent wash using cladosporium cladosporioides. Int J Environ Sci Tech 2011, 8:97-106.

27. Watanabe Y, Sugi R, Tanaka Y, Hayashida S: Enzymatic decolourization of melanoidin by Coriolus sp. Agr boil Chem 1982, 46:1623-1630.

28. Sirianuntapiboon S, Phothilangka P, Ohmomo S: Decolourization of molasses wastewater by a strain no. BP103 of acetogenic bacteria. Biores Technol 2004, 92:31-39.

29. Kirk TK, Schultz E, Connors WJ, Lorenz LF, Zeikus JG: Influence of culture parameter of lignin metabolism by P. chrysosporium. Arch Microbiol 1978, 117:177-185.

30. APHA, AWWA, WPCF, Standard: Methods for Examination of Water and Wastewater. twentiethth edition. Maryland, USA: United Book Press, Ind; 1998

31. Ohmomo S, Kainuma M, Kmimura K, Sirianuntapiboon S, Aoshima I, Atthasampunna P: Adsorption of melanoidin to the mycelia of Aspergillus oryzae Y-2-32. Agric Biol Chem 1988, 52:381-386.

32. Chavan MN, Kulkarani MV, Zope VP, Mahulikar PP: Microbial degradation of melanoidins in distillery spent wash by indigeneous isolate. Ind J Biotech 2006, 5:416-421.

doi:10.1186/1472-6750-12-30

Cite this article as: Tiwari et al:: Decolorization of a recalcitrant organic compound (Melanoidin) by a novel thermotolerant yeast, Candida tropicalis RG-9. BMC Biotechnology 2012 12:30. 